\title{
Pomalidomide - An Appraisal of Its Clinical Development and Role in the Treatment of Relapsed/Refractory Multiple Myeloma
}

\author{
Paul G Richardson, ${ }^{1}$ Antonio Palumbo, ${ }^{2}$ Stephen A Schey, ${ }^{3}$ Meletios A Dimopoulos, ${ }^{4}$ Thierry Facon, ${ }^{5}$ Katja C Weisel, ${ }^{6}$ \\ Peter O'Gorman, ${ }^{7}$ Xavier Leleu, ${ }^{8}$ Martha Q Lacy, ${ }^{9}$ Matthew J Streetly, ${ }^{10}$ Joseph R Mikhael, ${ }^{11}$ David S Siegel, ${ }^{12}$ Jesus F San Miguel ${ }^{13}$ \\ and Kenneth C Anderson ${ }^{14}$
}

\begin{abstract}
1. Clinical Director of the Myeloma Program, Dana-Farber Cancer Institute, Boston, MA, US; 2. Chief of the Myeloma Unit of the Department of Oncology, University of Torino, Torino, Italy; 3. Clinical Lead and Consultant Haematologist, Department of Haematology, King's College Hospital, London, UK; 4. Professor and Chairman, Department of Clinical Therapeutics, University of Athens School of Medicine, Athens, Greece; 5. Professor of Hematology, Lille University Hospital, Service des Maladies du Sang, Hôpital Claude Huriez, Lille, France; 6. Senior Physician, Department of Hematology, Oncology, Immunology, Rheumatology and Pulmonology, University Hospital of Tuebingen, Tuebingen, Germany; 7. Clinical Director of Pathology/Consultant Haematologist, Mater Misericordiae University Hospital, Dublin, Ireland; 8. Associate Professor, Department of Haematology, Lille University Hospital, Service des Maladies du Sang, Hôpital Claude Huriez, Lille, France; 9. Professor of Medicine, Chair of Hematology, Department of Internal Medicine, Mayo Clinic, Rochester, MN, US; 10. Consultant Haematologist and Clinical Lead for Myeloma, Department of Haematology, Guy's Hospital, Guy's and Thomas' NHS Foundation Trust, London, UK; 11. Associate Professor, Mayo Clinic, Scottsdale, AZ, US; 12. Chief, Multiple Myeloma Division, John Theurer Cancer Center, Hackensack, NJ, US; 13. Director of Clinical \& Translational Medicine, Clínica Universidad de Navarra, Centro de Investigación Médica Aplicada, IDISNA, Pamplona, Spain;

14. Program Director, Jerome Lipper Multiple Myeloma Center and LeBow Institute for Myeloma Therapeutics, Dana-Farber Cancer Institute, Boston, MA, US
\end{abstract}

\begin{abstract}
Pomalidomide is a distinct immunomodulatory agent with significant activity in relapsed/refractory multiple myeloma (RRMM). The optimal treatment schedule in patients with RRMM who have received multiple lines of treatment, including bortezomib and lenalidomide, is $4 \mathrm{mg} /$ day on days 1-21 of a 28-day cycle in combination with weekly low-dose dexamethasone. Improved responses and outcomes relative to traditional therapies continue to be confirmed in recently completed and ongoing trials. Pomalidomide exhibits direct tumoricidal, immunomodulatory, anti-angiogenic and anti-inflammatory activities, which facilitate combination therapy with agents with complementary mechanisms of action, resulting in greater anti-myeloma effects than single-agent therapy or previous combination therapies. For example, in combination with proteasome inhibitors and traditional chemotherapeutic agents in doublet or triplet regimens, pomalidomide provides high rates of durable response, and represents an important new treatment option for patients with RRMM requiring effective new therapies. Additionally, pomalidomide maintains its efficacy and tolerability profile in difficult-to-treat patients, including the elderly, patients with poor cytogenetics and those with renal impairment. This review summarises the clinical development of pomalidomide and discusses this effective agent for the treatment of patients with RRMM in the context of current myeloma treatment options, as well as potential future directions to further improve patient outcomes.
\end{abstract}

\section{Keywords}

Pomalidomide, lenalidomide, IMiD, immunomodulatory agent, relapsed/refractory multiple myeloma, treatment-resistant multiple myeloma

\begin{abstract}
Disclosure: Paul G Richardson has served on the advisory committee for Novartis, Celgene, Takeda and Johnson \& Johnson; Antonio Palumbo has received consultancy and honoraria from Celgene and Janssen; Stephen A Schey has received honoraria from Celgene; Meletios A Dimopoulos has received honoraria from Celgene, Janssen, Onyx, Amgen and Novartis; Thierry Facon has served on the speakers bureau for Celgene and received honoraria and consulting fees from them as well; Katja C Weisel has consulted for and received honoraria and travel support from Bristol-Myers Squibb, Amgen, Celgene and Janssen, has received research funding from Celgene and Janssen, has consulted for and received honoraria from Onyx, received travel support from Novartis and Takeda and has consulted for Noxxon; Peter O'Gorman has served as a member of the steering committee for the Celgene Optimism Trial; Xavier Leleu has received honoraria from Janssen, Celgene, Novartis, Bristol-Myers Squibb and Amgen; Martha Q Lacy has received research funding from Celgene; Matthew I Streetly has no relevant conflicts to share; Joseph R Mikhael has received grants from Celgene, Sanofi and Onyx; David S Siegel has received honoraria from Celgene and has served on the speakers bureau for Celgene, Amgen, Takeda, Novartis and Merck; Jesus F San Miguel has served on the advisory board for Millennium, Celgene, Novartis, Onyx, Janssen, Bristol-Myers Squibb and MSD; Kenneth C Anderson has received consultancy fees from Celgene, Millennium, BMS and Gilead, and has equity ownership in OncoPep and Acetylon.

Open Access: This article is published under the Creative Commons Attribution Noncommercial License, which permits any non-commercial use, distribution, adaptation and reproduction provided the original author(s) and source are given appropriate credit. DOl: http://doi.org/10.17925/EOH.2015.11.02.109 Received: 1 October 2015 Accepted: 28 October 2015 Citation: European Oncology \& Haematology, 2015;11(2):109-17

Correspondence: Paul G Richardson, MD, 450 Brookline Avenue, Medical Oncology, Boston, MA 02115, US. E: paul_richardson@dfci.harvard.edu
\end{abstract}

Support: The authors received editorial assistance from Peter J Simon, PhD, CMPP, of MediTech Media, sponsored by Celgene Corporation. Paul G Richardson received administrative support from Michelle E Maglio, supported by the RJ Corman MM Research Fund.

Multiple myeloma (MM) is an incurable disease characterised by accumulation of clonal plasma cells in the bone marrow and accounts for approximately $10 \%$ of all haematological malignancies. ${ }^{1}$ Advances in the understanding of $\mathrm{MM}$, better identification of high-risk patients, and the recent development of several novel agents have improved response and nearly doubled the length of time to disease 


\section{Figure 1: The Antimyeloma, Immunomodulatory and Stromal-support Inhibitory Effects of Pomalidomide}

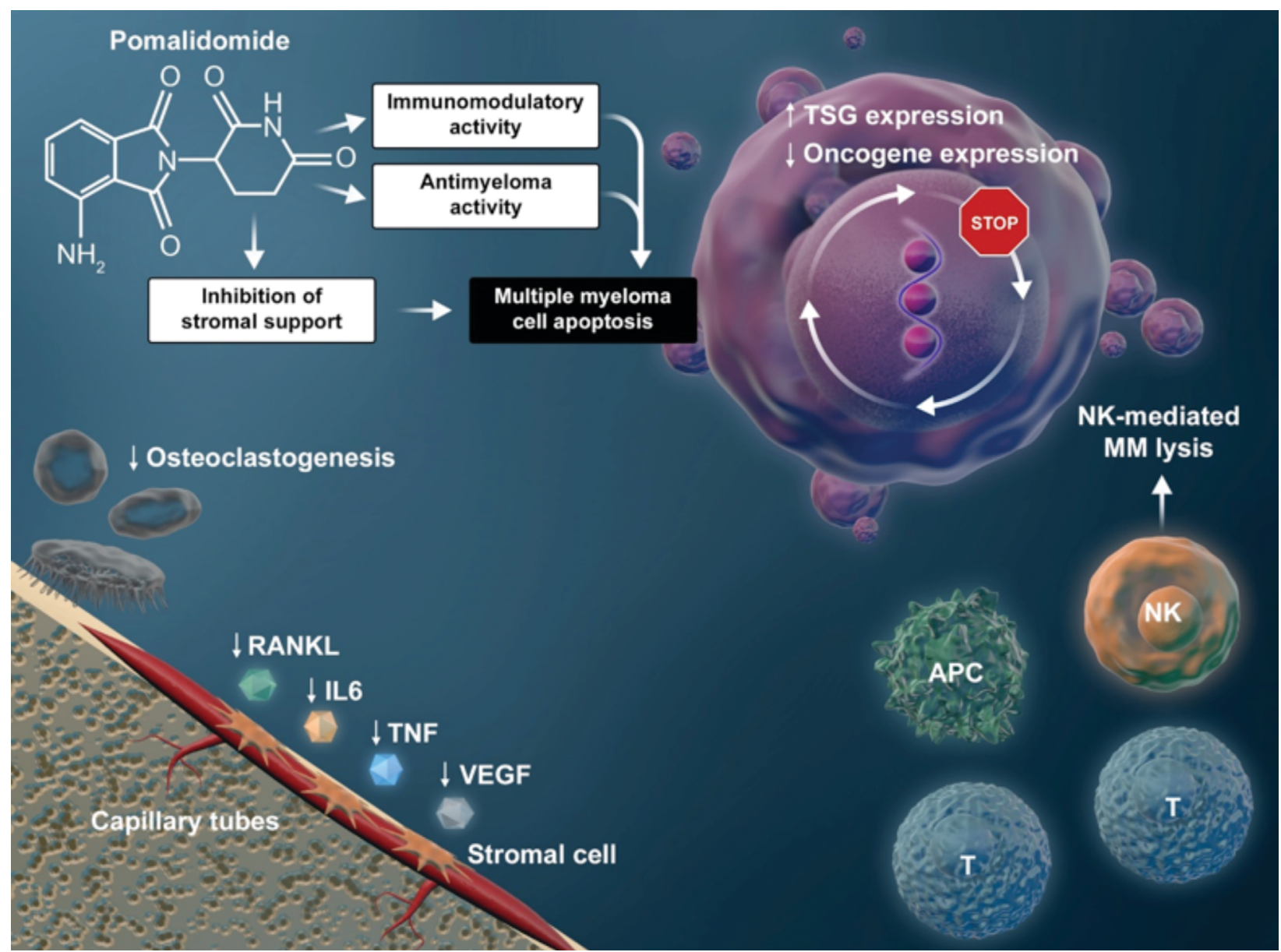

Pomalidomide has multiple mechanisms of action, including anti-angiogenic, antiproliferative, proapoptotic and stromal cell support inhibitory activity against chemotherapy- and lenalidomide-resistant multiple myeloma (MM) cells. APC = antigen-presenting cell; $I L=$ interleukin; $N K=$ natural killer; RANKL = receptor activator of nuclear factor $\kappa B$ ligand; TNF = tumour necrosis factor; TSG = tumour suppressor gene; VEGF = vascular endothelial growth factor. Adapted with permission from Mark TM, et al., Leukemia Research, 2014;38:517524, Copyright 2014, with permission from Elsevier.

progression, leading to overall survival (OS) on the order of 7 to 10 years. ${ }^{2-5}$ However, since almost all patients eventually relapse and become refractory to current standards of care, there is a constant need for effective new therapies and treatment regimens. Indeed, prognosis for patients who have become refractory to proteasome inhibitors (e.g., bortezomib) and lenalidomide is poor; with further treatment, median OS is at best 12 months; without further treatment, OS is dismal: 3 months. ${ }^{6}$ To that end, a number of next-generation novel agents have recently been approved in the US and in Europe ${ }^{7-10}$ for the treatment of patients with relapsed and refractory multiple myeloma (RRMM), in whom prior therapies including lenalidomide and bortezomib have failed; these include the immunomodulatory drug (IMiD) pomalidomide, the proteasome inhibitor carfilzomib and the deacetylase inhibitor panobinostat.

In particular, pomalidomide plus dexamethasone is approved both in the US and Europe for the treatment of patients with RRMM who have received $\geq 2$ prior therapies (including lenalidomide/thalidomide + bortezomib) and have progressed on treatment or within 60 days following completion of their last prior therapy.,10

We will describe the development of pomalidomide as a novel therapy for RRMM and will include discussion of the known mechanism of action, the establishment of the approved dose and schedule (phase
I studies), safety and efficacy trials in RRMM (phase II and III trials), and novel pomalidomide-based combinations being investigated. The review will then explore additional recent advances in the treatment of RRMM and the role of pomalidomide in this context. We will conclude with a discussion of the array of populations of patients with RRMM who may benefit from treatment with pomalidomide, including patients with renal impairment, patients with high-risk cytogenetics and the elderly.

\section{Proposed Mechanisms of Action}

Pomalidomide has potent antimyeloma and immunomodulatory activities as well as inhibitory effects on stroma cells ${ }^{11-17}$ that can facilitate combination therapy with agents with complementary mechanisms of action, resulting in significant antimyeloma effects and non-overlapping toxicities. The mechanisms of pomalidomide's pleiotropic antimyeloma effects are complex (see Figure 1). Direct tumoricidal activity is mediated by inhibition of DNA synthesis and proapoptotic signalling. ${ }^{12}$ Importantly, pomalidomide inhibits proliferation of lenalidomide-resistant $\mathrm{MM}$ cell lines ${ }^{18}$ and has synergistic activity with dexamethasone in both lenalidomide-sensitive and lenalidomide-resistant cells. ${ }^{19}$ This activity is potentially mediated through suppression of IRF4, a gene critical for myeloma cell growth, as well as suppression of expression of the protooncogene c-Myc to affect up-regulation of the cyclin-dependent kinase (CDK) inhibitor p21 ${ }^{\text {WAF-1 }}$ and cell cycle arrest. ${ }^{18}$ Immunomodulatory effects 
Table 1: Studies Informing the Pomalidomide Dose and Schedule

\begin{tabular}{|c|c|c|c|c|c|c|c|c|c|}
\hline Study & Phase & $\begin{array}{l}\text { Patients, } \\
\mathrm{n}\end{array}$ & $\begin{array}{l}\text { Prior } \\
\text { Regimens, } \\
\text { Median } \\
\text { (Range) }\end{array}$ & $\begin{array}{l}\text { Pomalidomide } \\
\text { Dose(s) and } \\
\text { Schedule }\end{array}$ & $\begin{array}{l}\text { Pomalidomide } \\
\text { MTD }\end{array}$ & $\begin{array}{l}\text { Adverse Events of } \\
\text { Interest (Grade } 3 \text { or } 4) \text {, } \\
\%\end{array}$ & $\begin{array}{l}\text { ORR } \\
(\geq P R), \%\end{array}$ & $\begin{array}{l}\text { PFS, } \\
\text { Months }\end{array}$ & OS, Months \\
\hline $\begin{array}{l}\text { Richardson, } \\
2013^{33} \\
\text { (MM-002) }\end{array}$ & I & 38 & $6(2-17)$ & $\begin{array}{l}2,3,4 \text { or } 5 \text { mg daily; } \\
\text { days } 1-21 \text { of } \\
\text { 28-day cycle }\end{array}$ & 4 mg daily & $\begin{array}{l}\text { Fatigue (66) } \\
\text { Neutropenia (61) } \\
\text { Anaemia (45) } \\
\text { Thrombocytopenia (26) } \\
\text { Pneumonia (13) }\end{array}$ & 21 & 4.6 & 18.3 \\
\hline Schey, $2004^{31}$ & I & 24 & $3(1-6)$ & $\begin{array}{l}1,2,5 \text { or } 10 \text { mg daily; } \\
\text { days } 1-28 \text { of } 28- \\
\text { day cycle }\end{array}$ & 2 mg/day & $\begin{array}{l}\text { Neutropenia (58) } \\
\text { Deep vein thrombosis (17) } \\
\text { Thrombocytopenia (13) }\end{array}$ & 54 & 9.0 & 20.7 \\
\hline Streetly, $2008^{32}$ & 1 & 20 & $4(1-7)$ & $\begin{array}{l}1,2,5 \text { or } 10 \mathrm{mg} \text { on } \\
\text { alternate days }\end{array}$ & $\begin{array}{l}5 \text { mg on } \\
\text { alternate days }\end{array}$ & $\begin{array}{l}\text { Neutropenia (45) } \\
\text { Thrombocytopenia (10) }\end{array}$ & 50 & 10.5 & 33 \\
\hline $\begin{array}{l}\text { Lacy, } 2009^{35} \\
\text { (Mayo Clinic } \\
\text { Study) }\end{array}$ & $\|$ & 60 & $2(1-3)$ & $\begin{array}{l}2 \text { mg daily; days 1-28 } \\
\text { of } 28 \text {-day cycle }\end{array}$ & NR & $\begin{array}{l}\text { Neutropenia (32) } \\
\text { Fatigue (17) } \\
\text { Pneumonia (8) } \\
\text { Anaemia (5) } \\
\text { Thrombocytopenia (3) }\end{array}$ & 63 & 11.6 & $\begin{array}{l}94 \% \text { at } \\
6 \text { months }\end{array}$ \\
\hline $\begin{array}{l}\text { Lacy, } 2010^{34} \\
\text { (Mayo } \\
\text { Clinic Study) }\end{array}$ & $\|$ & 34 & $4(1-7+)$ & $\begin{array}{l}2 \text { mg daily; days 1-28 } \\
\text { of } 28 \text {-day cycle }\end{array}$ & NR & $\begin{array}{l}\text { Neutropenia (29) } \\
\text { Anaemia (12) } \\
\text { Thrombocytopenia (9) } \\
\text { Fatigue (9) }\end{array}$ & 47 & 4.8 & 13.9 \\
\hline $\begin{array}{l}\text { Lacy, } 2011^{36} \\
\text { (Mayo } \\
\text { Clinic Study) }\end{array}$ & $\|$ & 35 & $6(3-9)$ & $\begin{array}{l}2 \text { mg daily; days 1-28 } \\
\text { of 28-day cycle }\end{array}$ & $\mathrm{NR}$ & $\begin{array}{l}\text { Neutropenia (51) } \\
\text { Pneumonia (31) } \\
\text { Fatigue (9) }\end{array}$ & 26 & 6.5 & $\begin{array}{l}78 \% \text { at } \\
6 \text { months }\end{array}$ \\
\hline & & 35 & $6(2-11)$ & $\begin{array}{l}4 \text { mg daily; days 1-28 } \\
\text { of 28-day cycle }\end{array}$ & & $\begin{array}{l}\text { Neutropenia (66) } \\
\text { Fatigue (9) }\end{array}$ & 28 & 3.2 & $\begin{array}{l}67 \% \text { at } \\
6 \text { months }\end{array}$ \\
\hline
\end{tabular}

$M T D=$ maximum tolerated dose; $N R=$ not reported; ORR = overall response rate; $O S=$ overall survival; $P F S=$ progression-free survival; $P R=$ partial response

of pomalidomide include enhancement of T-cell- and natural killer cellmediated immunity. ${ }^{11,20-22}$

Further immunomodulatory activity of pomalidomide is mediated through inhibition of the production of pro-inflammatory cytokines, including tumor necrosis factor $\alpha$ (TNF- $\alpha$ ) and interleukin 6 (IL-6). ${ }^{11}$ T-cell and TNF- $\alpha$ immunomodulatory activities of pomalidomide and other immunomodulatory agents (thalidomide and lenalidomide) have recently been shown to be regulated by their binding to the ubiquitously expressed E3 ubiquitin ligase protein cereblon to affect T-cell activation. ${ }^{18,23,24}$ Pomalidomide and lenalidomide promote binding of the transcriptional repressors of IL-2 expression, Ikaros and Aiolos, to cereblon, thereby facilitating the subsequent ubiquitin-mediated proteosomal degradation of these repressors in T-lymphocytes. Hence, pomalidomide-enhanced, and thus cereblon-mediated, degradation of Ikaros and Aiolos promotes T-cell activation through de-repression of IL-2. ${ }^{25-27}$

Similar to its analogue thalidomide, pomalidomide has antiangiogenic effects, as demonstrated by in vitro angiogenesis assays. ${ }^{28}$ Pomalidomide also has anti-inflammatory effects that are due, in part, to elevation of IL-10 production and subsequent inhibition of cyclooxygenase-2 expression. ${ }^{29,30}$

The complex and diverse activities of pomalidomide in both chemotherapy- and lenalidomide-resistant cells not only make it an attractive therapy for patients with refractory disease but also allow for the design of combination therapy regimens that take advantage of nonoverlapping toxicities and complementary mechanisms of action. Such pomalidomide combination regimens have in turn been assessed in trials that have studied such combinations and will be discussed below.

\section{Establishment of Approved Dose and Schedule}

Several early-phase trials evaluated dose-limiting toxicities in order to determine the maximum tolerated dose and the optimal treatment schedule of pomalidomide in patients with RRMM who had previously received multiple lines of treatment, including bortezomib and Ienalidomide (see Table 1). Initially, pomalidomide was explored as a single agent before being investigated in combination with dexamethasone. ${ }^{31,32}$ The approved dose was based on the data from MM-002, which assessed pomalidomide at 2, 3, 4 or $5 \mathrm{mg} /$ day doses in combination with $40 \mathrm{mg}$ weekly dexamethasone. ${ }^{33}$ The most commonly reported grade 3 or 4 treatment-emergent adverse events in MM-002 were neutropenia, anaemia, thrombocytopenia and fatigue (53\%, $21 \%, 18 \%$ and $16 \%$, respectively). Except for one case of grade 3 fatigue in a patient in the pomalidomide $2 \mathrm{mg}$ cohort, all of the doselimiting toxicities in this study were grade 4 neutropenia and occurred across the 3, 4 and $5 \mathrm{mg}$ dosing levels. ${ }^{33}$ The maximum tolerated dose and schedule for which pomalidomide has been approved in RRMM is $4 \mathrm{mg}$ per day on days 1-21 of a 28-day cycle in combination with $40 \mathrm{mg}$ weekly dexamethasone, although other doses and schedules were analysed for pomalidomide monotherapy ${ }^{31,32}$ and in combination with low-dose dexamethasone. . $3-36^{-36}$

\section{Clinical Trials Aimed at Assessing Safety and Outcomes}

Multiple studies have examined the safety and efficacy of pomalidomide at the approved dose and schedule in combination with low-dose dexamethasone. Table 2 summarises the key results of the MM-002 phase II study as well as the Intergroupe Francophone du Myélome 2009-02 (IFM 2009-02) phase II study, the Mayo phase II study and the MM-003 and STRATUSTM (MM-010) phase III studies, 
Table 2: Results From Key Pomalidomide Phase II and Phase III Studies Assessing 4 mg per Day on Days 1-21 of a 28-day Cycle in Combination With Low-dose Dexamethasone

\begin{tabular}{|c|c|c|c|c|c|c|c|c|}
\hline Study & Phase & $\begin{array}{l}\text { Patients, } \\
\mathrm{n}\end{array}$ & $\begin{array}{l}\text { Prior } \\
\text { Regimens, } \\
\text { Median } \\
\text { (Range) }\end{array}$ & POM Treatment Arms* & $\begin{array}{l}\text { Adverse Events of } \\
\text { Interest (Grade } 3 \text { or } 4 \text { ), } \\
\%\end{array}$ & $\begin{array}{l}\text { ORR } \\
\text { ( } \geq \text { PR), \% }\end{array}$ & $\begin{array}{l}\text { PFS, } \\
\text { Months }\end{array}$ & OS, Months \\
\hline \multirow[t]{2}{*}{$\begin{array}{l}\text { Richardson, } \\
2014^{37} \text { (MM-002) }\end{array}$} & $\|$ & $\begin{array}{l}113(\mathrm{POM}+ \\
\mathrm{LODEX})\end{array}$ & $5(1-13)$ & POM + LODEX & $\begin{array}{l}\text { Neutropenia (41) } \\
\text { Anaemia (22) } \\
\text { Pneumonia (22) } \\
\text { Thrombocytopenia (19) }\end{array}$ & $33^{+}$ & $4.2^{\ddagger}$ & 16.5 \\
\hline & & 108 (РOM) & & POM & $\begin{array}{l}\text { Neutropenia (48) } \\
\text { Anaemia (24) } \\
\text { Thrombocytopenia (22) } \\
\text { Pneumonia (15) }\end{array}$ & 18 & 2.7 & 13.6 \\
\hline $\begin{array}{l}\text { Lacy, 2012 } \\
\text { (Mayo Clinic } \\
\text { Study) }\end{array}$ & $\|$ & 120 & $3(1-14)$ & POM + LODEX§ & $\begin{array}{l}\text { Neutropenia (31) } \\
\text { Anaemia (16) } \\
\text { Thrombocytopenia (12) } \\
\text { Pneumonia (8) } \\
\text { Fatigue (8) }\end{array}$ & 21 & 4.3 & NR \\
\hline $\begin{array}{l}\text { Leleu, } \\
2013^{39} \\
\text { (IFM 2009-02) }\end{array}$ & $\|$ & 43 & $5(1-13)$ & POM + LODEX & $\begin{array}{l}\text { Anaemia (37) } \\
\text { Neutropenia (65) } \\
\text { Thrombocytopenia (28) }\end{array}$ & 35 & 5.4 & 14.9 \\
\hline \multirow[t]{2}{*}{$\begin{array}{l}\text { San Miguel, } \\
2013^{40} \text { (MM-003) }\end{array}$} & III & $\begin{array}{l}302(\mathrm{POM}+ \\
\text { LODEX) }\end{array}$ & $5(2-14)$ & POM + LODEX & $\begin{array}{l}\text { Neutropenia (48) } \\
\text { Anaemia (33) } \\
\text { Thrombocytopenia (22) }\end{array}$ & $31 \|$ & $4 \|$ & $12.7 \pi$ \\
\hline & & 153 (DEX) & $5(2-17)$ & $\begin{array}{l}\text { DEX: } 40 \text { mg days } 1-4,9-12 \\
17-20 \text { (20 mg if age > } 75 \text { y) }\end{array}$ & $\begin{array}{l}\text { Anaemia (37) } \\
\text { Thrombocytopenia (26) } \\
\text { Neutropenia (16) }\end{array}$ & 10 & 1.9 & 8.1 \\
\hline $\begin{array}{l}\text { Dimopoulos, } \\
2015^{42} \\
\text { (MM-010/ } \\
\text { STRATUS) }\end{array}$ & IIIb & 676 & $4(2-18)$ & $\begin{array}{l}\text { POM + LODEX (20 mg if age } \\
>75 \mathrm{y})\end{array}$ & $\begin{array}{l}\text { Neutropenia (42) } \\
\text { Anaemia (29) } \\
\text { Thrombocytopenia (22) } \\
\text { Pneumonia (11) }\end{array}$ & 33 & 4.4 & 12.0 \\
\hline
\end{tabular}

*Pomalidomide (POM) $4 \mathrm{mg} 21$ of 28 days, dexamethasone (DEX) $40 \mathrm{mg}$ weekly, unless otherwise noted; ${ }^{\dagger} p=0.013$ versus POM; $\neq p=0.003$ versus POM; ${ }^{s}$ Results for Cohort 6 (days $1-21$ of 28-day cycles); " $p<0.0001$ versus POM; " $p<0.03$ versuS DEX. LODEX = low-dose dexamethasone; NR = not reported; ORR = overall response rate; OS = overall survival; PFS = progression-free survival.

which all assessed the safety and clinical efficacy of pomalidomide + dexamethasone for the treatment of RRMM. The pivotal phase II portion of MM-002 evaluated pomalidomide alone or in combination with lowdose dexamethasone. ${ }^{37}$ All patients had to have received $\geq 2$ prior antimyeloma therapies, including $\geq 2$ cycles of Ienalidomide and $\geq 2$ cycles of bortezomib, which were given separately or in combination, and had to have relapsed after having achieved at least stable disease for $\geq 1$ cycle of treatment with $\geq 1$ prior regimen. The patients' RRMM must have progressed during or within 60 days of their completing treatment with the regimen used just prior to study entry (defining relapsed and refractory disease). ${ }^{37}$ Overall response rate (ORR; $\geq$ partial response) was significantly higher with pomalidomide + low-dose dexamethasone compared with pomalidomide alone (33\% versus $18 \%, p=0.013$ ) with a median follow-up of 14.2 months. ${ }^{37}$ Progressionfree survival (PFS) was also greater in the pomalidomide + low-dose dexamethasone group (4.2 versus 2.7 months; $p=0.003$ ). Importantly, refractoriness to lenalidomide or resistance to both lenalidomide and bortezomib did not affect outcomes with pomalidomide + low-dose dexamethasone. Pomalidomide + low-dose dexamethasone showed significantly greater PFS than pomalidomide alone in the subset of patients with lenalidomide-refractory disease (3.8 versus 2.2 months; $\mathrm{p}=0.042$ ) and trended towards greater PFS in patients with lenalidomideand bortezomib-refractory disease ( 3.8 versus 2.0 months; $p=0.150$ ). ${ }^{37}$ The median OS was 16.5 and 13.6 months in the pomalidomide + lowdose dexamethasone and pomalidomide alone groups, respectively. ${ }^{37}$ This compares favourably with historically reported 9-month survival rates in patients in whom currently approved novel agents have failed. ${ }^{6}$ The results of the MM-002 study confirmed those of earlier studies in which $4 \mathrm{mg}$ pomalidomide on days 1-21 of a 28-day cycle + weekly low-dose dexamethasone was assessed for the treatment of RRMM ${ }^{38,39}$ Thus, the studies described here demonstrated that there is no cross-resistance between pomalidomide and lenalidomide in patients who had received prior treatment with lenalidomide or lenalidomide + bortezomib.

Further evidence for the effectiveness of pomalidomide + low-dose dexamethasone in patients whose disease was refractory to lenalidomide or both lenalidomide and bortezomib has recently been demonstrated in two phase III studies. ${ }^{40-42}$ In the multinational MM-003 trial, pomalidomide + low-dose dexamethasone versus high-dose dexamethasone was assessed in 455 patients with refractory MM or RRMM who had failed at least two previous treatments of bortezomib and lenalidomide..$^{40}$ With a median follow-up of 15.4 months, longer PFS (4.0 versus 1.9 months, hazard ratio [HR]: 0.50; $p<0.001)$ was achieved in patients receiving the combination of pomalidomide + low-dose dexamethasone versus high-dose dexamethasone alone. ${ }^{41}$ This PFS benefit was also seen in patients with lenalidomide-refractory disease (HR 0.51 [95\% confidence interval (Cl), 0.41-0.64]) and lenalidomide- and bortezomib-refractory disease (HR 0.53 [95 \% Cl $0.42-0.68$ ]). In the final OS analysis, median OS was significantly longer in patients treated with the combination (13.1 versus 8.1 months, HR 0.72; $\mathrm{p}=0.009$ )..$^{41}$ Indeed, the OS of 13.1 months in the pomalidomide + low-dose dexamethasone arm compares 
very favourably with the 9-month survival rates for patients in whom currently approved novel agents have failed. ${ }^{6}$ The most common grade $3 / 4$ haematological adverse events in the pomalidomide + low-dose dexamethasone and high-dose dexamethasone groups, respectively, were neutropenia (48 \% versus $16 \%$ ), anaemia (33\% versus $37 \%$ ) and thrombocytopenia (22\% versus $26 \%$ ). ${ }^{40}$

The phase III MM-010 study is the largest conducted to date with pomalidomide + low-dose dexamethasone in a heavily pretreated RRMM patient population (median four prior therapies; $80 \%$ refractory to Ienalidomide and bortezomib). ${ }^{42}$ Treatment with pomalidomide + low-dose dexamethasone resulted in an ORR of $33 \%$ with a median PFS and OS of 4.4 and 12.0 months, respectively. ${ }^{42}$ Importantly, these results were similar to those in the subgroup of patients refractory to lenalidomide or lenalidomide + bortezomib: PFS of 4.4 and 4.2 months, respectively, and OS of 12.0 months for each. The most common grade $3 / 4$ treatment-emergent adverse events were haematological and included neutropenia (48\%), anaemia (31\%) and thrombocytopenia (23\%). ${ }^{42}$ MM-010 confirmed the findings of MM-002 and MM-003, and demonstrated that the combination of pomalidomide + low-dose dexamethasone should be considered a standard of care for patients with RRMM in whom lenalidomide and bortezomib treatment has failed.

In a pooled analysis of six trials comprising 641 patients treated with pomalidomide + low-dose dexamethasone for lenalidomide and bortezomib dual-refractory RRMM, response rates were found to be consistent, with an ORR of $31 \% .{ }^{43}$ In both the pooled analysis and MM010 , the ORR in patients aged $>65$ years was $32 \%{ }^{43,44}$ The incidence of grade $3 / 4$ neutropenia in MM-010 $(48 \%)^{42}$ was slightly lower than that reported in the pooled analysis (53\%). ${ }^{43}$ These findings should, however, be interpreted with caution, as trial populations are heterogeneous and responses, outcomes and adverse event rates vary between trials.

\section{Novel Combinations with Pomalidomide}

The encouraging results of pomalidomide in combination with dexamethasone and its favourable toxicity profile have provided the impetus to explore combination regimens of pomalidomide with other antimyeloma drugs in the relapsed/refractory setting. Since additive toxicities among agents may be avoided or minimised by judicious selection of agents with non-overlapping toxicities and mechanisms of action, unique combinations may result in additive or synergistic antimyeloma effects. Pomalidomide's manageable toxicity profile could allow longer duration of therapy, thus providing durable responses that may be augmented by the addition of antimyeloma therapies with complementary mechanisms of action to help achieve a deeper response. While the association of depth of treatment response to outcomes is not universal across studies, improvements in the quality of response (depth and durability) across all stages of treatment are associated with better disease control and longer survival. ${ }^{45,46}$ It should also be considered that exposure of malignant cells to a single agent often results in preferential overactivation of alternate cell survival pathways that could be targeted using other agents with alternative mechanisms of action. ${ }^{45}$

Table 3 summarises early-phase trials and encouraging results of some pomalidomide-based combination studies in RRMM. For example, since pomalidomide retains activity in patients with lenalidomide- and bortezomib-refractory disease, $33,37-40,42$ pomalidomide + dexamethasone is therefore a logical backbone for combination therapy in patients with RRMM who are refractory to lenalidomide and/or bortezomib. Similarly, the combination of pomalidomide, bortezomib and dexamethasone is a rational approach to treating patients who are refractory to lenalidomide. Indeed, high responses (approximately 70-80\%) have been seen in early-phase trials assessing this combination in lenalidomide-refractory patients..$^{47,48}$ Initial results of a phase I study assessing the triplet therapy of pomalidomide (4 mg/day, days $1-21$ of a 28 -day cycle), bortezomib (1 mg weekly) and low-dose dexamethasone have demonstrated the utility of this regimen in 47 patients with RRMM..$^{48} \mathrm{~A}$ large proportion of these patients were high-risk (del[17p], t[4;16] or t[14;20]) by fluorescent in situ hybridisation [FISH] or high-risk gene expression profiling [GEP] signature) ${ }^{5}$ and heavily pretreated. Response rates were $84 \%$ in 19 high-/intermediate-risk (t[4;14] by FISH, cytogenetic del[13], hypodiploidy or plasma cell labelling index $\geq 3 \%$ ) patients and $86 \%$ in 28 standard-risk patients (all other patients including t[11;14] and t[6;14]). Median PFS was 9.5 months in high-/intermediate-risk patients and 16.3 months in standard-risk patients. ${ }^{48}$ The most common adverse events (including those grade $\geq 3$ ) were haematological and included anaemia, thrombocytopenia and neutropenia. ${ }^{48}$ This combination is being further explored (versus bortezomib + dexamethasone) in the ongoing phase III trial OPTIMISMM [NCT01734928] with an expected enrollment of 782 patients with RRMM. ${ }^{49}$ The results of this trial are eagerly awaited, as they will help address the question of whether adding pomalidomide to bortezomib and dexamethasone will provide a deep response and extend the duration of response compared with bortezomib and dexamethasone salvage therapy. Similar to the combination of pomalidomide, bortezomib and dexamethasone, the combination of pomalidomide, carfilzomib and dexamethasone has also provided high rates of response, with acceptable safety profiles. ${ }^{50-52}$ Larger studies are needed to confirm these results and are under way.

The results of the OPTIMISMM trial will likely be considered in the context of results from ENDEAVOR, a phase III trial $(n=929)$ in RRMM in which the carfilzomib + dexamethasone arm had a median PFS nearly twice that of the bortezomib + dexamethasone arm: 18.7 versus 9.4 months. ${ }^{53}$ However, the significant improvement in PFS is also tempered by an increase in grade $\geq 3$ adverse events of interest in the carfilzomib arm: hypertension (9 \% versus $3 \%$ ), dyspnoea (preferred term; $5 \%$ versus $2 \%$ ), cardiac failure (5\% versus $2 \%$ ) and acute renal failure (4\% versus $3 \%)^{53}$ Indeed, the safety results from ENDEAVOR are not dissimilar to those of the single-agent carfilzomib arm of the FOCUS trial. ${ }^{54}$ Overall, caution may be warranted when using carfilzomib in patients with cardiac comorbidities or who have received prior therapy with cardiotoxic agents. ${ }^{55}$

Combinations of pomalidomide and cytotoxic agents have been evaluated in early-phase trials in patients with RRMM. The combination of pomalidomide, cyclophosphamide and prednisone was evaluated in a phase I/II trial, with a reported ORR of $51 \% .^{56}$ The combination of pomalidomide, cyclophosphamide and dexamethasone was evaluated in a phase II study and demonstrated superior ORR (65\%) and PFS (median 9.2 months) versus pomalidomide plus dexamethasone (ORR of $39 \%$ and median PFS of 4.4 months). ${ }^{57}$ The combination of pomalidomide, dexamethasone and clarithromycin was evaluated in a phase II study, with a reported ORR of $60 \% .^{58}$ Additionally, reduced-dose pomalidomide, dexamethasone and pegylated liposomal doxorubicin has been evaluated in a phase I/II trial in lenalidomide-refractory patients and demonstrated an ORR of $43 \%$ and a good tolerability profile. ${ }^{59}$

Pomalidomide is also being evaluated in combination with the anti-CD38 monoclonal antibodies daratumumab and isatuximab (SAR650984). The 
Table 3: Key Results of Recent Pomalidomide Combination Studies

\begin{tabular}{|c|c|c|c|c|c|c|c|c|c|c|}
\hline Study & $\begin{array}{l}\text { Combination } \\
\text { Therapy }\end{array}$ & Phase & $\begin{array}{l}\text { Patients, } \\
\mathrm{n}\end{array}$ & $\begin{array}{l}\text { Prior } \\
\text { Regimens, } \\
\text { Median } \\
\text { (Range) }\end{array}$ & $\begin{array}{l}\text { Dose(s)/ } \\
\text { Schedule } \\
\text { Evaluated* }\end{array}$ & $\begin{array}{l}\text { Median } \\
\text { Follow-up, } \\
\text { Months }\end{array}$ & $\begin{array}{l}\text { Adverse Events } \\
\text { of Interest } \\
\text { (Grade } 3 \text { or } 4 \text { ), \% }\end{array}$ & $\begin{array}{l}\text { ORR } \\
\text { ( } \geq \text { PR), \% }\end{array}$ & $\begin{array}{l}\text { PFS, } \\
\text { Months }\end{array}$ & $\begin{array}{l}\text { OS, } \\
\text { Months }\end{array}$ \\
\hline $\begin{array}{l}\text { Larocca, } \\
2013^{56}\end{array}$ & $\begin{array}{l}\text { POM + } \\
\text { cyclophosphamide } \\
\text { + prednisone }\end{array}$ & $|/| \mid$ & $\begin{array}{l}55 \text { treated } \\
\text { at MTD }\end{array}$ & $3(1-3)$ & $\begin{array}{l}\text { POM: } 2.5 \text { mg } \\
\text { daily } \\
\text { Cyclophosphamide: } \\
50 \text { mg every other day } \\
\text { Prednisone: } 50 \text { mg } \\
\text { every other day }\end{array}$ & 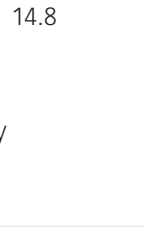 & $\begin{array}{l}\text { Neutropenia (42) } \\
\text { Thrombocytopenia (11) } \\
\text { Anaemia (9) } \\
\text { Neurological (7) } \\
\text { Dermatological (7) }\end{array}$ & 51 & 10.4 & $\begin{array}{l}\text { Median not } \\
\text { reached; } \\
69 \% \text { at } \\
1 \text { year }\end{array}$ \\
\hline \multirow[t]{2}{*}{$\begin{array}{l}\text { Baz, } \\
2014^{57}\end{array}$} & $\begin{array}{l}\text { POM + } \\
\text { cyclophosphamide } \\
+ \text { DEX }\end{array}$ & $\|$ & 34 & $4(2-12)$ & $\begin{array}{l}\text { POM: } 4 \text { mg daily } \\
\text { Cyclophosphamide: } \\
400 \text { mg days } 1,8,15 \\
\text { of } 28 \text {-day cycle } \\
\text { DEX: } 40 \text { mg weekly } \\
\text { (20 mg if age > } 75 \text { y) }\end{array}$ & 15 & $\begin{array}{l}\text { Neutropenia (50) } \\
\text { Anaemia (20) } \\
\text { Febrile neutropenia (18) } \\
\text { Thrombocytopenia (11) }\end{array}$ & $65^{+}$ & $9.2^{\ddagger}$ & 10.5 \\
\hline & $P O M+D E X$ & & 36 & & & & $\begin{array}{l}\text { Neutropenia (33) } \\
\text { Febrile neutropenia (11) } \\
\text { Pneumonia (11) } \\
\text { Anaemia (8) }\end{array}$ & 39 & 4.4 & 16.4 \\
\hline $\begin{array}{l}\text { Mark, } \\
2011^{58}\end{array}$ & $\begin{array}{l}\text { Clarithromycin + } \\
\text { POM + DEX }\end{array}$ & $\|$ & 52 & $6(2-10)$ & $\begin{array}{l}\text { Clarithromycin: } \\
500 \text { mg twice daily } \\
\text { POM: } 4 \text { mg daily } \\
\text { DEX: } 40 \text { mg weekly }\end{array}$ & 6.7 & $\begin{array}{l}\text { Neutropenia (46) } \\
\text { Lymphopenia (35) } \\
\text { Thrombocytopenia (30) } \\
\text { Anaemia (17) }\end{array}$ & 60 & NR & NR \\
\hline $\begin{array}{l}\text { Shah, } \\
2012^{52}\end{array}$ & $\mathrm{CFZ}+\mathrm{POM}+\mathrm{DEX}$ & $|/| \mid$ & 12 & $6(2-15)$ & $\begin{array}{l}\text { CFZ: } 20-27 \text { mg/m² } \\
\text { days 1, 2, 8, 9, 15, } 16 \\
\text { POM: } 4 \text { mg daily } \\
\text { DEX: } 40 \text { mg weekly }\end{array}$ & NR & $\begin{array}{l}\text { Neutropenia (56) } \\
\text { Anaemia (41) } \\
\text { Thrombocytopenia (28) }\end{array}$ & 50 & NR & NR \\
\hline $\begin{array}{l}\text { Stadtmauer, } \\
2013^{83}\end{array}$ & $\mathrm{CFZ}+\mathrm{POM}+\mathrm{DEX}$ & $|/| \mid$ & 12 & 6 & $\begin{array}{l}\text { CFZ: } 20-36 \text { mg/m² } \\
\text { days 1, 2, 8, 9, 15, } 16 \\
\text { POM: } 4 \text { mg daily } \\
\text { DEX: } 40 \text { mg weekly }\end{array}$ & NR & $\begin{array}{l}\text { DLTS and SAES: } \\
\text { Pneumonia (50) } \\
\text { Thrombocytopenia (33) } \\
\text { Rash (33) }\end{array}$ & NR & $\begin{array}{l}\text { 6-month } \\
\text { PFS, } 71 \%\end{array}$ & $\begin{array}{l}90 \% \text { at } \\
1 \text { year }\end{array}$ \\
\hline $\begin{array}{l}\text { Rosenbaum, } \\
2014^{51}\end{array}$ & $C F Z+P O M+D E X$ & $\mid \mathrm{b} / \mathrm{II}$ & 25 & $2(1-6)$ & $\begin{array}{l}\text { CFZ: } 20-36 \mathrm{mg} / \mathrm{m}^{2} \\
\text { days } 1,2,8,9,15,16 \\
\text { POM: 3-4 mg daily } \\
\text { DEX: } 20-40 \text { mg weekly }\end{array}$ & 10 & $\begin{array}{l}\text { Neutropenia (32) } \\
\text { Lymphopenia (25) } \\
\text { Hypophosphataemia (14) }\end{array}$ & 76 & 18.9 & NR \\
\hline $\begin{array}{l}\text { Richardson, } \\
2014^{47} \\
\text { (MM-005) }\end{array}$ & $\mathrm{POM}+\mathrm{BORT}+\mathrm{DEX}$ & 1 & 28 & $2(1-4)$ & $\begin{array}{l}\text { POM: } 4 \mathrm{mg} \text { days } 1-14 \\
\text { of } 21 \text {-day cycle } \\
\text { BORT: } 1.3 \mathrm{mg} / \mathrm{m}^{2} \\
\text { (days } 1,4,11 \text { for cycles } \\
\text { 1-8 and days } 1,8 \text { for } \\
\text { cycles } 9+\text { ) } \\
\text { DEX: } 20 \mathrm{mg} \text { (10 mg for } \\
\text { pts age > } 75 \text { y) days 1- } \\
4-5,8-9,11-12 \text { for } \\
\text { cycles } 1-8 \text { and days } 1-2 \\
\text { and } 8-9 \text { for cycles } 9+\end{array}$ & 2 & $\begin{array}{l}\text { Neutropenia (36) } \\
\text { Thrombocytopenia (27) }\end{array}$ & $67-71$ & NR & NR \\
\hline $\begin{array}{l}\text { Lacy, } \\
2014^{48}\end{array}$ & $\mathrm{POM}+\mathrm{BORT}+\mathrm{DEX}$ & $|/| \mid$ & $\begin{array}{l}47 \text { treated } \\
\text { at MTD }\end{array}$ & 3 & $\begin{array}{l}\text { POM: } 4 \mathrm{mg} \text { daily } \\
\text { BORT: } 1.3 \mathrm{mg} / \mathrm{m}^{2} \\
\text { (days } 1,8,15,22 \text { ) } \\
\text { DEX: } 40 \mathrm{mg} \text { weekly }\end{array}$ & 9 & $\begin{array}{l}\text { Neutropenia (62) } \\
\text { Leukopenia (32) } \\
\text { Lymphopenia (17) } \\
\text { Lung infection (13) }\end{array}$ & $81^{\S}$ & 18 & $\begin{array}{l}96 \% \text { alive } \\
\text { at } 9 \text { months }\end{array}$ \\
\hline $\begin{array}{l}\text { Mateos, } \\
2015^{60}\end{array}$ & $\mathrm{POM}+\mathrm{DARA}+\mathrm{DEX}$ & $\mathrm{Ib}$ & 24 & $4(2-9)$ & $\begin{array}{l}\text { POM: } 4 \text { mg } \\
\text { DEX: } 40 \text { mg weekly } \\
\text { (20 mg for pts age } \\
\text { >75 y) DARA: Dose NR, } \\
\text { given weekly for } 2 \\
\text { cycles, every other } \\
\text { week for } 4 \text { cycles, } \\
\text { then every } 4 \text { weeks } \\
\text { for } 7 \text { cycles }\end{array}$ & 29 days & NA & 55 & NR & NR \\
\hline
\end{tabular}

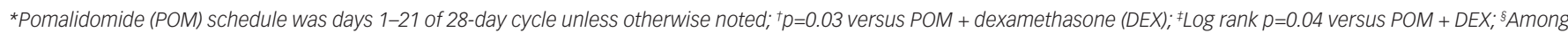
42 evaluable patients. $B O R T=$ bortezomib; $C F Z=$ carfilzomib; $D A R A=$ daratumumab; $M T D=$ maximum tolerated dose; $N A=$ not available; NR = not reported; ORR = overall response rate; $O S=$ overall survival; $P F S=$ progression-free survival; $P$ TS = patients. 
safety and tolerability of daratumumab combined with pomalidomide and dexamethasone was investigated in 24 patients in a recent phase $\mathrm{Ib}$ study..$^{60}$ Patients who had received $\geq 2$ consecutive cycles of bortezomib and lenalidomide and had refractory or relapsed and refractory multiple myeloma received the approved dose of pomalidomide and dexamethasone and weekly daratumumab (for cycles 1 and 2, then every other week for cycles 3-6, and every 4 weeks for seven cycles). The most common adverse events were haematological and were likely related to pomalidomide. The ORR was $55 \%$, with a median time to first response of 31 days (range, 29-57 days). ${ }^{60}$

Although results are not yet available for the combination of isatuximab with pomalidomide, some early data have emerged for isatuximab with lenalidomide. A phase Ib study assessing lenalidomide, isatuximab, and dexamethasone in a heavily pretreated RRMM population demonstrated that this combination was well tolerated and yielded rapid and durable responses: the median time to first response was 4.2 weeks and the duration of response was 23.1 weeks. ${ }^{61}$ With a median follow-up of 6.0 months, median PFS was 6.2 months..$^{61}$ Importantly, in addition to the responses being evident following the first cycle of therapy and deepening thereafter, the ORR was $63 \%$ in patients who were refractory to their last regimen containing lenalidomide. ${ }^{61} \mathrm{~A}$ phase $\mathrm{Ib}$ study is currently recruiting and will assess the safety, pharmacokinetics, duration of response, and preliminary efficacy of pomalidomide, isatuximab and dexamethasone in patients with RRMM (NCT02283775). ${ }^{62}$

\section{Special Populations that May Benefit from Pomalidomide Therapy}

RRMM may be particularly challenging to treat in patients with comorbidities or other factors that may limit dose intensity or duration of therapy. When selecting a therapeutic regimen, physicians must consider associated toxicities and the fitness of patients who receive these therapies. Patient populations for which this approach may be especially important include the elderly, patients with renal disease and patients with high-risk cytogenetics.

\section{Elderly}

As the general population ages, treatment of the elderly RRMM patient must be increasingly considered. Although not always, elderly patients are often ineligible for high-dose chemotherapy and autologous stem cell transplant. Effective therapies that are associated with limited toxicities are therefore needed. Pomalidomide at $4 \mathrm{mg}$ has been shown to be an appropriate starting dose in patients with RRMM regardless of age. ${ }^{44}$ In a recent subanalysis of the MM-010 study assessing $4 \mathrm{mg}$ pomalidomide + low-dose dexamethasone ( $40 \mathrm{mg}$ weekly $\leq 75$ years, $20 \mathrm{mg}$ weekly $>75$ years), Palumbo et al., ${ }^{44}$ examined outcomes by age ( $\leq 65$ versus $>65$ years, and $\leq 70$ versus $>70$ years). ORR was consistent for patients aged $\leq 65(34 \%),>65(32 \%), \leq 70(32 \%)$ and $>70(34 \%)$ years. ${ }^{44}$ Median PFS was also similar across all age groups (PFS range, 4.2-4.7 months). ${ }^{44}$ Similar toxicity rates were noted across the age groups. Grade $3 / 4$ adverse effects included neutropenia (47-48 \%), anaemia (29-31\%), thrombocytopenia (18-25\%) and pneumonia (10-13\%). ${ }^{44}$ These results support those of previous subanalyses of the MM-002 and MM-003 trials assessing the efficacy and safety of pomalidomide by age. ${ }^{63,64}$ Pomalidomide and low-dose dexamethasone has therefore been shown to be an effective treatment option for RRMM regardless of age.

\section{Renal Impairment}

Renal impairment is a common comorbidity in patients with $\mathrm{MM}$, with $>20 \%$ of patients ultimately experiencing renal failure. ${ }^{65}$ Pomalidomide is extensively metabolised prior to excretion, but since $10 \%$ is excreted unchanged in the urine, ${ }^{66}$ clinically relevant nephrotoxicity is limited. This is similar to thalidomide, but distinct from lenalidomide, which excretes $>80 \%$ of the parent compound in urine. ${ }^{67,68}$ Pharmacokinetic data indicate similar mean dose-normalised exposure of pomalidomide in patients with RRMM with severe renal impairment (creatinine clearance $[\mathrm{CrCl}]<30 \mathrm{~mL} /$ minute; including patients requiring and not requiring dialysis) and those with normal renal function ( $\mathrm{CrCl} \geq 90 \mathrm{~mL} /$ minute) or mild renal impairment ( $\mathrm{CrCl} \geq 60$ to $<90 \mathrm{~mL} /$ minute) at the approved $4 \mathrm{mg}$ dose. ${ }^{69}$ Pomalidomide clearance is not significantly affected by renal function (as measured by $\mathrm{CrCl}$ or renal impairment). ${ }^{70}$ Similarly, in a study of clarithromycin + pomalidomide + dexamethasone, baseline renal function as well as hepatic function were found not to be predictive of dose reduction. ${ }^{71}$ In renally impaired patients, pomalidomide + lowdose dexamethasone has an acceptable safety and efficacy profile comparable to that observed in patients without renal impairment. In several studies, response to pomalidomide + low-dose dexamethasone and tolerability were consistent across renal function subgroups, with few discontinuations due to adverse effects. ${ }^{.174}$ These results were most recently supported by an analysis of patients with RRMM and renal impairment in the MM-010 STRATUS trial. ${ }^{75}$ In patients with moderate renal impairment ( $\mathrm{CrCl} \geq 30$ to $<60 \mathrm{~mL} /$ minute), treatment with pomalidomide + low-dose dexamethasone had a manageable safety profile and was efficacious. Tolerability was similar in patients with or without moderate renal impairment, which was consistent with results from the MM-002 and MM-003 trials. ${ }^{37,40}$ Despite differences in patients' renal function, ORRs were consistent between groups. Although there was a slightly longer median PFS in patients without moderate renal impairment, this did not meet statistical significance $(p=0.1644) .{ }^{75}$ However, data in patients with severe renal impairment $(\mathrm{CrCl}<30 \mathrm{~mL} /$ minute) remain limited. Use of pomalidomide should be avoided in patients with a serum creatinine level $>3.0 \mathrm{mg} / \mathrm{dL}^{\text {? }}$

\section{High-risk Cytogenetics}

Patients with $\mathrm{MM}$ and high-risk cytogenetics (such as del[17p] and t[4;14]) have an early relapse rate and shorter survival. ${ }^{76,77}$ However, in patients with RRMM receiving salvage therapy with pomalidomide + low-dose dexamethasone, high-risk cytogenetics do not appear to affect outcomes in non-heavily pretreated patients ${ }^{76}$ or heavily pretreated patients. ${ }^{78-80}$ This combination is therefore effective and has been shown in several studies to be well tolerated in patients with RRMM and adverse cytogenetics, particularly those with del(17p), a patient population that often rapidly becomes refractory to therapy and has a poor prognosis. ${ }^{77,81}$ However, the relationship between specific cytogenetic abnormalities, risk and response to therapy is less defined. Indeed, some studies have shown differential effects of specific abnormalities, ${ }^{39}$ and additional studies are needed in this area.

\section{Conclusions}

Pomalidomide is a distinct immunomodulatory agent that, in combination with low-dose dexamethasone, has significant activity in patients with RRMM in whom prior lenalidomide and bortezomib have failed, a patient population for whom there are limited treatment options and that constitutes an important unmet medical need. Importantly, pomalidomide's activity is maintained in difficult-to-treat patient subgroups, including the elderly, patients with adverse cytogenetics and those with renal impairment. Moreover, its favourable tolerability profile and manageable toxicity make it additionally attractive as a therapeutic option, especially in combination and given the active dose range seen with its use, which in turn allows a tailored approach to its 
use. $^{82}$ In addition, the pleiotropic mechanism of action of pomalidomide, including direct tumoricidal, immunomodulatory, anti-angiogenic and anti-inflammatory activity, indicates that pomalidomide can be used in combination with agents that have complementary mechanisms of action to provide a greater antimyeloma effect than single-agent therapy or previous combination therapies. Indeed, pomalidomide in combination with proteasome inhibitors and traditional chemotherapeutic agents in doublet or triplet regimens is providing high rates of response that are durable. These studies and other pomalidomide-based combinations with various novel therapies are especially important new treatment options for patients with RRMM, for whom effective new therapies are urgently required.
1. Dimopoulos MA, Kastritis E, Anagnostopoulos A, Hematological malignancies: myeloma, Ann Oncol, 2006;17 Suppl. 10:x137-43.

2. McCarthy PL, Owzar K, Hofmeister CC, et al., Lenalidomide after stem-cell transplantation for multiple myeloma, N Engl J Med, 2012;366:1770-81

3. Kumar SK, Dispenzieri A, Lacy MQ, et al., Continued improvement in survival in multiple myeloma: changes in early mortality and outcomes in older patients, Leukemia, 2014;28:1122-8

4. Kumar SK, Rajkumar SV, Dispenzieri A, et al., Improved survival in multiple myeloma and the impact of novel therapies, Blood, 2008;111:2516-20.

5. Mikhael JR, Dingli D, Roy V, et al., Management of newly diagnosed symptomatic multiple myeloma: updated Mayo Stratification of Myeloma and Risk-Adapted Therapy (mSMART) consensus guidelines, 2013, Mayo Clin Proc, 2013;88:360-76.

Kumar SK, Lee JH, Lahuerta JJ, et al., Risk of progression and
survival in multiple myeloma relapsing after therapy with survival in multiple myeloma relapsing after therapy with
IMiDs and bortezomib: a multicenter International Myeloma Working Group study, Leukemia, 2012;26:149-57.

. Pomalyst (pomalidomide) [package insert]. Summit, $\mathrm{NJ}$ : Celgene Corporation; 2015.

8. Farydak (panobinostat) [package insert]. East Hanover, NJ: Novartis Pharmaceuticals Corporation; 2015

9. Kyprolis (carfilzomib) [package insert]. South San Francisco, CA: Onyx Pharmaceuticals; 2015.

10. Imnovid (pomalidomide) [summary of product characteristics] Uxbridge, UK: Celgene Europe; 2015.

11. Corral LG, Haslett PA, Muller GW, et al., Differential cytokine modulation and T cell activation by two distinct classes of thalidomide analogues that are potent inhibitors of TNF-alpha, J Immunol, 1999:163:380-6.

12. Hideshima T, Chauhan D, Shima Y, et al., Thalidomide and its analogs overcome drug resistance of human multiple myeloma cells to conventional therapy, Blood, 2000:96:2943-50.

13. Mitsiades N, Mitsiades CS, Poulaki V, et al., Apoptotic signaling induced by immunomodulatory thalidomide analogs in human multiple myeloma cells: therapeutic implications, Blood, 2002; 99:4525-30

14. Verhelle $D$, Corral LG, Wong $K$, et al., Lenalidomide and CC-4047 inhibit the proliferation of malignant B cells while expanding normal CD34+ progenitor cells, Cancer Res, 2007;67:746-55

15. Henry JY, Labarthe M, Meyer B, et al., Enhanced crosspriming of naive CD8+T cells by DCs treated by the IMiDS $^{\oplus}$ immunomodulatory compounds lenalidomide and pomalidomide, Immunology, 2013:139:377-85.

16. Gupta D, Treon SP, Shima Y, et al., Adherence of multiple myeloma cells to bone marrow stromal cells upregulates vascular endothelial growth factor secretion: therapeutic applications, Leukemia, 2001:15:1950-61.

17. Bolzoni M, Abeltino M, Storti P, et al., The immunomodulatory drugs lenalidomide and pomalidomide inhibit multiple myeloma-induced osteoclast formation and RANKL/OPG Ratio in myeloma microenvironment targeting the expression of adhesion molecules, Blood, 2010;116:201 [abstract 448].

18. Lopez-Girona A, Mendy D, Ito T, et al., Cereblon is a direct protein target for immunomodulatory and antiproliferative activities of lenalidomide and pomalidomide, Leukemia, 2012;26:2326-35.

19. Rychak E, Mendy D, Miller K, et al., Overcoming resistance: the use of pomalidomide (pom) and dexamethasone (dex) in re-sensitizing lenalidomide (len)-resistant multiple myeloma (MM) cells. Poster presented at European Hematology (MM) cells. Poster presented at European Hemato

20. Davies FE, Raje N, Hideshima T, et al., Thalidomide and immunomodulatory derivatives augment natural killer cell cytotoxicity in multiple myeloma, Blood, 2001;98:210-6.

21. Payvandi F, Wu L, Naziruddin SD, et al., Immunomodulatory drugs (IMiDs) increase the production of IL-2 from stimulated T cells by increasing PKC-theta activation and enhancing the DNA-binding activity of AP-1 but not NF-kappaB, OCT-1, or NF-AT, I Interferon Cytokine Res, 2005;25:604-16.

22. Reddy N, Hernandez-llizaliturri FJ, Deeb G, et al., Immunomodulatory drugs stimulate natural killer-cell function, alter cytokine production by dendritic cells, and inhibit angiogenesis enhancing the anti-tumour activity of rituximab in vivo, Br J Haematol, 2008;140:36-45.

23. Zhu $Y X$, Braggio $E$, Shi $C X$, et al., Cereblon expression is required for the anti-myeloma activity of lenalidomide and pomalidomide, Blood, 2011:4771-9.

24. Zhu YX, Kortuem KM, Stewart AK., Molecular mechanism of action of immune-modulatory drugs thalidomide, lenalidomide and pomalidomide in multiple myeloma, Leuk Lymphoma, 2013;54:683-7.

25. Gandhi AK, Kang J, Havens CG, et al., Immunomodulatory agents lenalidomide and pomalidomide co-stimulate T cells by inducing degradation of T cell repressors Ikaros and Aiolos via modulation of the E3 ubiquitin ligase complex
CRL4(CRBN), Br J Haematol, 2014:164:811-21.

26. Kronke J, Udeshi ND, Narla A, et al., Lenalidomide causes selective degradation of IKZF1 and IKZF3 in multiple myeloma cells, Science, 2014:343:301-5.

27. Lu G, Middleton RE, Sun $H$, et al., The myeloma drug lenalidomide promotes the cereblon-dependent destruction of Ikaros proteins, Science, 2014;343:305-9.

28. Lu L, Payvandi F, Wu L, et al., The anti-cancer drug lenalidomid inhibits angiogenesis and metastasis via multiple inhibitory effects on endothelial cell function in normoxic and hypoxic conditions, Microvasc Res, 2009;77:78-86.

29. Payvandi F, Wu L, Haley M, et al., Immunomodulatory drugs inhibit expression of cyclooxygenase-2 from TNF-alpha, IL-1beta, and LPS-stimulated human PBMC in a partially IL-10dependent manner, Cell Immunol, 2004;230:81-8.

30. Ferguson GD, Jensen-Pergakes K, Wilkey C, et al., Immunomodulatory drug CC-4047 is a cell-type and stimulusselective transcriptional inhibitor of cyclooxygenase $2, J$ Clin selective transcriptional in

31. Schey SA, Fields P, Bartlett JB, et al., Phase I study of an immunomodulatory thalidomide analog, CC-4047, in relapsed or refractory multiple myeloma, J Clin Oncol, 2004;22:3269-76.

32. Streetly MJ, Gyertson K, Daniel Y, Zeldis JB, Kazmi M, Sche SA., Alternate day pomalidomide retains anti-myeloma effect with reduced adverse events and evidence of in vivo immunomodulation, Br J Haematol, 2008;141:41-51.

33. Richardson PG, Siegel D, Baz R, et al., Phase 1 study of pomalidomide MTD, safety, and efficacy in patients with refractory multiple myeloma who have received Ienalidomide and bortezomib, Blood, 2013;121:1961-7.

34. Lacy MQ, Hayman SR, Gertz MA, et al., Pomalidomide (CC4047) plus low dose dexamethasone (Pom/dex) is active and well tolerated in lenalidomide refractory multiple myeloma (MM), Leukemia, 2010:24:1934-9.

35. Lacy MQ, Hayman SR, Gertz MA, et al., Pomalidomide (CC4047) plus low-dose dexamethasone as therapy for relapsed multiple myeloma, J Clin Oncol, 2009;27:5008-14.

36. Lacy MQ, Allred JB, Gertz MA, et al., Pomalidomide plus low-dose dexamethasone in myeloma refractory to both bortezomib and lenalidomide: comparison of 2 dosing strategies in dual-refractory disease, Blood, 2011;118:2970-5.

37. Richardson PG, Siegel DS, Vij R, et al., Pomalidomide alone or in combination with low-dose dexamethasone in relapsed and refractory multiple myeloma: a randomized phase 2 study, Blood, 2014;123:1826-32.

38. Lacy MQ, Kumar SK, LaPlant BL, et al., Pomalidomide plus lowdose dexamethasone (Pom/Dex) in relapsed myeloma: Iong term follow up and factors predicing outcome in 345 patients, Blood, 2012;120 [abstract 201].

39. Leleu X, Attal M, Arnulf $B$, et al. Pomalidomide plus low dose dexamethasone is active and well tolerated in bortezomib and lenalidomide-refractory multiple myeloma: Intergroupe Francophone du Myélome 2009-02, Blood, 2013;121:1968-75.

40. San Miguel J, Weisel K, Moreau P, et al., Pomalidomide plus low-dose dexamethasone versus high-dose dexamethasone alone for patients with relapsed and refractory multiple myeloma (MM-003): a randomised, open-label, phase 3 trial, Lancet Oncol, 2013;14:1055-66.

41. San Miguel JF, Weisel KC, Song KW, et al., Impact of prior treatment and depth of response on survival in MM-003, a randomized phase 3 study comparing pomalidomide plus low-dose dexamethasone versus high-dose dexamethasone in relapsed/refractory multiple myeloma, Haematologica, 2015;100:1334-9.

42. Dimopoulos MA, Palumbo A, Corradini P, et al., The STRATUS (MM-010) trial: a single-arm, phase 3B study evaluating safety and efficacy of pomalidomide + low-dose dexamethasone in patients with refractory or relapsed and refractory multiple myeloma, Haematologica, 2015;100 [abstract P273].

43. Sheng Z, Liu G, Pooled analysis of the reports of pomalidomide after failure of lenalidomide and (or) bortezomib for multiple myeloma, Hematol Oncol, 2015 [Epub ahead of print].

44. Palumbo A, Moreau P, Dimopoulos M, et al., Outcomes for older patients with refractory or relapsed and refractory multiple myeloma treated with pomalidomide + low-dose dexamethasone in the STRATUS (MM-010) trial, a single-arm, phase 3B study, Haematologica, 2015;100 [abstract P272].

45. Lonial S, Mitsiades CS, Richardson PG, Treatment options for relapsed and refractory multiple myeloma, Clin Cancer Res, 2011;17:1264-77.

46. Lonial S, Anderson KC, Association of response endpoints with survival outcomes in multiple myeloma, Leukemia 2014;28:258-68.

47. Richardson P, Hofmeister C, Noopur R, et al., MM-005: phase trial of pomalidomide (POM) bortezomib (BORT, and low-dose dexamethasone (LODEX [PVD]) in lenalidomide (LEN) refractory and proteasome inhibitor (PI)-exposed myeloma, J Clin Oncol, 2014;32:8589.

48. Lacy M, LaPlant B, Laumann K, et al., Pomalidomide, bortezomib and dexamethasone (PVD) for patients with relapsed lenalidomide refractory multiple myeloma (MM), Blood, 2014:124 [abstract 304].

49. National Institutes of Health, Safety and efficacy of pomalidomide, bortezomib and low-dose dexamethasone in subjects with relapsed or refractory multiple myeloma (OPTIMISMM), Available at: https://clinicaltrials.gov/ct2/show NCT01734928 (accessed September 4, 2015).

50. Stadtmauer E, Shah J, Abonour R, et al., Pomalidomide and dexamethasone (CPOmd) for relapsed/refractory multiple myeloma (RRMM): a phase I/II trial, Clin Lymphoma Myeloma Leuk, 2013;13(suppl 1) [abstract P-250].

51. Rosenbaum C, Kukreti V, Zonder J, et al., Phase 1b/2 study of carfilzomib, pomalidomide, and dexamethasone (KPd) in patients (pts) with lenalidomide-exposed and/or -refractory but proteasome inhibitor (PI)-naive or -sensitive multiple myeloma: a Multiple Myeloma Research Consortium multicenter study, Blood, 2014;124 [abstract 2109].

52. Shah JJ, Stadtmauer EA, Abonour R, et al., A multi-center phase 1/ll trial of carfilzomib and pomalidomide with dexamethasone (Car-Pom-d) in patients with relapsed/refractory multiple myeloma, Oral presentation at: ASH Annual Meeting, Atlanta, GA, 8-11 December 2012 [abstract 74]

53. Dimopoulos M, Moreau P, Palumbo A, et al., Carfilzomib and dexamethasone improves progression-free survival and response rates vs bortezomib and dexamethasone in patient (pts) with relapsed multiple myeloma (RMM): the phase 3 study ENDEAVOR, Haematologica, 2015;100 [abstract LB2071].

54. Ludwig H, Masszi T, Petrucci MT, et al., Carfilzomib (K) vs lowdose corticosteroids and optional cyclophosphamide (CY) in patients (pts) with relapsed and refractory multiple myeloma (RRMM): results from a phase 3 study (FOCUS), Ann Oncol, 2014:25 [abstract LBA28].

55. Atrash S, Tullos A, Panozzo S, et al., Cardiac complications in relapsed and refractory multiple myeloma patients treated with carfilzomib, Blood Cancer J, 2015;5:e272.

56. Larocca A, Montefusco V, Bringhen S, et al., Pomalidomide, cyclophosphamide, and prednisone for relapsed/refractory multiple myeloma: a multicenter phase 1/2 open-label study, Blood, 2013;122:2799-806

57. Baz R, Martin T, Alsina M, et al., Pomalidomide, cyclophosphamide, and dexamethasone is superior to pomalidomide and dexamethasone in relapsed and refractory myeloma: results of a multicenter randomized phase II study, Blood, 2014;124 [abstract 303]

58. Mark TM, Rodriguez M, Shah M, et al., ClaPD (clarithromycin/ $\left[\right.$ Biaxin $\left.^{\circledast}\right]$, pomalidomide, dexamethasone) therapy in relapsed or refractory multiple myeloma, Oral presentation at: ASH Annual Meeting, San Diego, CA, 10-13 December 2011 [abstract 291]

59. Berenson JR, Stampleman L, Bessudo A, et al., Safety and efficacy of pomalidomide (POM), dexamethasone (DEX), and pegylated liposomal doxorubicin (PLD) for patients with relapsed/refractory multiple myeloma (RRMM), J Clin Oncol, 2015;33 [abstract 8591]

60. Mateos MV, Moreau P, Comenzo R, et al., An open-label, multicenter, phase $1 \mathrm{~B}$ study of daratumumab in combination with pomalidomide-dexamethasone and with backbone regimens in patients with multiple myeloma, Haematologica 2015;100 [abstract P275].

61. Martin T, Baz R, Benson D, et al., A phase Ib dose escalation trial of SAR650984 (anti-CD-38 mAb) in combination with lenalidomide and dexamethasone in relapsed/refractory multiple myeloma, Blood, 2014;124 [abstract 83].

62 National Institutes of Health, SAR650984, pomalidomide and dexamethasone in combination in RRMM patients (PomdeSAR), Available at: https://clinicaltrials.gov/ct2/show/ NCT02283775 (accessed 4 September 2015).

63. Jagannath S, Hofmeister CC, Siegel DS, et al., Pomalidomide (POM) with low-dose dexamethasone (LoDex) in patients (pts) with relapsed and refractory multiple myeloma who have received prior therapy with lenalidomide (LEN) and bortezomib (BORT): updated phase 2 results and age subgroup analysis, Blood, 2012;120 [abstract 450].

64. Weisel KC, San Miguel JF, Song KW, et al., MM-003 phase 3 study of pomalidomide in combination with low-dose dexamethasone (POM + LODEX) vs high-dose dexamethasone (HiDEX) in relapsed/refractory multiple myeloma (RRMM): $\mathrm{POM}+$ LODEX is beneficial for elderly patients $(>65$ years of age). Poster presentation at: ASH Annual Meeting, New Of age). Poster presentation at: ASH Annual Meeting $\mathrm{N}$.

65. Eleutherakis-Papaiakovou V, Bamias A, Gika D, et al., Renal failure in multiple myeloma: incidence, correlations, and prognostic significance, Leuk Lymphoma, 2007;48:337-41.

66. Hoffmann M, Kasserra C, Reyes J, et al., Absorption, metabolism and excretion of [14C]pomalidomide in humans following oral administration, Cancer Chemother Pharmacol, 2013;71:489-501.

67. Surapaneni S, Stoltz M, Hilhorst M, et al., Mass balance, 
metabolism, and excretion of $14 \mathrm{C}$-thalidomide in healthy human subjects, Drug Metab Rev, 2009;41:66-7.

68. Chen $\mathrm{N}$, Wen $\mathrm{L}$, Lau $\mathrm{H}$, et al., Pharmacokinetics, metabolism and excretion of [(14)C]-lenalidomide following oral administration in healthy male subjects, Cancer Chemother Pharmacol, 2012;69:789-97.

69. Matous J, Siegel D, Lonial S, et al., MM-008: a phase 1 trial evaluating pharmacokinetics and tolerability of pomalidomide + low-dose dexamethasone in patients with relapsed or refractory and refractory multiple myeloma and renal impairment, Blood, 2014;124 [abstract 4730].

70. Li Y, XU Y, LiU L, et al., Population pharmacokinetics of pomalidomide, I Clin Pharmacol, 2015;55:563-72.

71. Rossi A, Aneja E, Boyer A, et al., Effect of renal and hepatic function on pomalidomide dose in patients with relapsed/ refractory multiple myeloma, Blood, 2014;124 [abstract 4754]

72. Siegel DS, Richardson PG, Baz R, et al., Pomalidomide (POM) with low-dose dexamethasone (LODEX) in patients with relapsed and refractory multiple myeloma (RRMM): impact of renal function on patient outcomes, Blood, 2012;120 [abstract 4072]

73. Weisel K, Dimopoulos M, Moreau P, et al., Pomalidomide plus low-dose dexamethasone (POM + LODEX) versus high-dose dexamethasone (HIDEX) in relapsed/refractory multiple myeloma (RRMM): MM-003 analysis of patients (pts) with moderate renal impairment (RI), J Clin Oncol, 2013;31 [abstract 8527]

74. Vij R, Richardson PG, Siegel DS, et al., Pomalidomide plus low-dose dexamethasone (POM + LODEX) in RRMM: analyses based on prior therapy and renal function, Clin Lymphoma Myeloma Leuk, 2013;13 [abstract P-170].

75. Weisel K, Dimopoulos MA, Palumbo A, et al., Analysis of patients with refractory or relapsed and refractory multiple patients with refractory or relapsed and refractory multiple myeloma and renal impairment treated with pomalidomide + low-dose dexamethasone in the phase 3B STRATUS
(MM-010), Haematologica, 2015;100 [abstract P286].

76. Leleu X, Karlin L, Macro M, et al., Pomalidomide plus low-dose dexamethasone in multiple myeloma with deletion $17 p$ and/or translocation (4;14): IFM 2010-02 trial results, Blood, 2015;125:1411-7.

77. Avet-Loiseau $\mathrm{H}$, Attal $\mathrm{M}$, Campion $\mathrm{L}$, et al., Long-term analysis of the IFM 99 trials for myeloma: cytogenetic abnormalities [t(4;14). del(17p), 1q gains] play a major role in defining longterm survival, J Clin Oncol, 2012;30:1949-52.

78. Richardson $\mathrm{P}$, Lonial $\mathrm{S}$, Jakubowiak $\mathrm{A}$, et al., Impact of POM+LODEX on disease parameters and cytogenetic status in relapsed and refractory multiple myeloma (RRMM), Clin Lymphoma Myeloma Leuk, 2013:13: [abstract 0-15]

79. Dimopoulos MA, Weisel KC, Song KW, et al., Final analysis, cytogenetics, long-term treatment, and long-term survival in MM-003, a phase 3 study comparing pomalidomide + low-dose dexamethasone (POM + LODEX) vs high-dose dexamethasone (HiDEX) in relapsed/refractory multiple myeloma (RRMM), Oral presentation at: ASH Annual Meeting, New Orleans, LA, 7-10 December 2013 [abstract 408].

80. Usmani S, Stratton $K$, Hansen $E$, et al., Final results of a phase II study of pomalidomide (Pom) in GEP-defined high risk II study of pomalidomide (POM) in GEP-defined high risk
relapsed and refractory multiple myeloma (RRMM), Blood, 2013;122 [abstract 3191]

81. Avet-Loiseau $H$, Attal M, Moreau P, et al., Genetic abnormalities and survival in multiple myeloma: the experience of the Intergroupe Francophone du Myélome, Blood, 2007;109:3489-95.

82. Laubach JP, Voorhees PM, Hassoun H, et al., Current strategies for treatment of relapsed/refractory multiple myeloma, Expert Rev Hematol, 2014;7:97-111.

83. Stadtmauer E, Shah J, Abonour R, et al., Carfilzomib,

pomalidomide and dexamethasone (CPOMd) for relapsed/ refractory multiple myeloma (RRMM): a phase I/II trial, Clin Lymphoma Myeloma Leuk, 2013;13 [abstract P-250].

84. Mark TM, Coleman M, Niesvizky R, Preclinical and clinical results with pomalidomide in the treatment of relapsed/ refractory multiple myeloma, Leuk Res, 2014;38:517-24. 